\title{
Assessing Indigenous Knowledge through Farmers' Perception and Adaptation to Climate Change in Pakistan
}

\author{
Muhammad Faisal Ali*, Muhammad Ashfaq, Sarfraz Hassan, Raza Ullah \\ Institute of Agricultural and Resource Economics, University of Agriculture, Faisalabad, Pakistan
}

Received: 3 August 2017

Accepted: 10 February 2018

\begin{abstract}
Integrating local perceptions and indigenous knowledge along with climate change policies has always been a neglected issue in developing countries. The approaches used are mostly originated from western concepts, developed in totally different socio-economic, cultural and political environments without recognizing local resources, individual opinions and knowledge. The present study tries to fill this gap and emphasizes the realization of the importance of need and transmission of modern scientific knowledge to local communities. So, the broader objective was to examine farmers' perceptions about climate change and other environmental issues through their indigenous knowledge. For this purpose, data was collected by interviewing 386 farmers from three different agro-ecological zones of Punjab Province, Pakistan. The methods used were problem cataloging index, weighted averages index and constraint index. Results indicated climate change as the biggest environmental problem, whereas scientists and the media were credited as the two most effective and reliable sources for climate information dissemination. In order to handle the issue of climate change, government, local councils and business and industry were assumed to be highly responsible, but farmers did not trust them. Although farmers' perceive climate change, due to many constraints very few of them were adapting accordingly. The major constraints were lack of money, high cost of farm inputs and lack of knowledge about appropriate adaptations. Findings suggest that inclusion of indigenous people in the decisionmaking process about local and national adaptation initiatives will help policy makers collaborate with local residents more effectively in order to better deal with the crisis of climate change.
\end{abstract}

Keywords: climate change, indigenous knowledge, perception, adaptation, farmers

\section{Introduction}

Climate change has become a convinced hazard in the way of realizing sustainable development

*e-mail: faisalaliuaf@gmail.com goals. It greatly affects the living conditions of the poor as they have very low adaptation capacity; furthermore, their livelihoods are greatly dependent on agriculture, which in turn is highly reliant on climate $[1,2]$. Although several attempts have been made by developing countries through government and nongovernmental organizations to assist the adaptation 
process, unfortunately they have failed to recognize the goals and aspirations of the local community as these approaches were totally based on western concepts developed in totally different socio-economic, cultural and political environments [3]. In other words, local resources, individual opinions and knowledge were not recognized while formulating the policies.

Pakistan is greatly exposed to extreme weather events due to changing climate $[4,5]$. According to the global climate risk index, Pakistan was the $8^{\text {th }}$ most affected country due to climate change during the period 1995-2014 [6]. Furthermore, the frequency and severity of extreme events is likely to increase due to predicted climate change [7]. Therefore, serious implications for agriculture are conveyed, and more crop losses are expected to happen that ultimately affect the economy of Pakistan $[8,9]$.

The use of indigenous knowledge is not a new concept. It has been used and discussed in literature but when we talk about climate change, a little scholarly work is available that addresses indigenous knowledge in the formulation of more viable and sustainable climate policies [10]. The knowledge accumulated across generations is usually termed as indigenous knowledge that mostly exists in oral form only and emerges from shared practices, experiences and storytelling that is reinforced by the experience of trial and error. Indigenous knowledge is holistic, integrative and situated within the border of cultural traditions primarily belonging to a specific location; therefore, it might not be applicable and transferable to other places [11].

Public belief about the importance and existence of climate change is strongly linked to their perception about local climate variations [12, 13]. Lack of firsthand experience for possible consequences of climate change has been indicated as one of the major reasons that people may not take actions to mitigate climate change or adapt accordingly, while on the other hand people who experience climate change directly would be more concerned and persuaded to proceed with sustainable behaviors [14]. But it is important to realize that noticeable impacts of climate change produce opportunities for individuals to become more confident about the reality of climate change, or does prior belief certainty shapes public perceptions through a process of motivated reasoning [15]. It is also required to frame the indigenous knowledge and climate concerns of local residents so that transmission of modern scientific knowledge can be effectively planned. Hence, the objective of this study is to examine a farmers' perception about climate change through indigenous knowledge.

This study identified the role of indigenous knowledge in adaptation to climate change in four steps. Firstly, we identify and ranked different environmental issues based on farmers' perceived rate of importance for each environmental issue. Secondly, the level of responsibility and trust on different stakeholders is assumed to take actions to minimize the negative consequences of climate change in Pakistan is determined. Thirdly, the importance of indigenous knowledge in climate change adaptation was analyzed by identifying the rate of self-reported adaptive mechanisms and coping strategies. In the end, potential constraints in adaptation to climate change were ranked based on the degree of constraint.

This paper has been divided into five sections. The first section introduces the study carried out along a brief review of literature in the second section. The third section explains the methodological framework followed to obtain the results, while the fourth part describes the results and a discussion on findings. The last section concludes the research and highlights some policy suggestions and recommendations based on the results.

\section{Review of Literature}

Although a limited scholarly evidence is available on climate change perception, research conducted so far has indicated that an individual's views on environmental issues and perceptions about climate change can be linked to an individual's experiences and physical surroundings. For example, people living in low-lying coastal areas have been identified with a sharp sense of potential future risks [16]. There is some evidence that the experience of a disaster and environmental problem can influence the views and perceptions of the local residents [17]. Physical vulnerability and experience that can be attributable to climate change indicated variations in perception about climate change and also in support for related policies on mitigation and adaptation [16, 17].

Historically, indigenous knowledge has remained a key source for rural farming communities in adapting to a constantly varying and changing climate [18] that provides the potential for locally relevant and sustainable adaptation strategies in agriculture under changing climate [19-21]. Furthermore, collaboration between indigenous knowledge and scientific research is suggested as a new coproduced knowledge that is pertinent in an operational adaptation plan at the local level [22], as knowledge is always learned, identified and applied within a farmers' cultural setting [21]. Furthermore, indigenous knowledge is a place base knowledge and is therefore essential in planning local interventions and policies at the local level. Although the importance of indigenous knowledge in adapting to climate change is imperative but a little empirical work is available on this issue in Pakistan. Hence this study is based on the assessment of indigenous knowledge and adaptation to climate change in the agriculture sector. Incorporating indigenous knowledge in climate change policies and intervention will lead to the development of an effective adaptation plan including cost-effective, participatory and locally relevant adaptation strategies that are sustainable [23]. 
Farmers' perception and indigenous knowledge about climate change is connected to awareness and further education of farmers and lowering the technological and financial capacities of farmers. Ineffective climate policy is also limiting the current support for adaptation to climate change in the agriculture sector. Hence, for a well-targeted adaptation policy there is need to integrate indigenous factors shaping the farmers perception and their adaptive responses [24]. The importance of indigenous knowledge is also realized while designing and implementing development projects. So, integrating local perception and indigenous knowledge into climate change policies would help formulate a more costeffective, participatory and sustainable way out for the issue of climate change adaptation and mitigation strategies [23].

\section{Methodology}

The study was conducted in three different agroecological zones of Punjab Province, which is the main agricultural area of the country. One district from each agro-ecological zone was selected purposively. The districts under study were Rajan Pur, Jhang and Rawalpindi. Cross-sectional data was collected by interviewing 386 farmers through a well-structured, pre-tested questionnaire. Farmers' perceptions and indigenous knowledge about climate change was represented by using some basic descriptive statistical tools, i.e., frequencies, percentages and means. The extent of environmental problems, levels of responsibility and trust and degrees of constraint in adaptation processes were estimated using a problem cataloging index (PCI), weighted average index (WAI) and constraint index (CI). We adapted these methodologies from Uddin, et al., (2014) and Ndamani and Watanabe (2015) [25-27], where weighted average index (WAI) was applied to assess farmers' perceived adaptation strategies in Bangladesh and barriers of adaptation to climate change in Nepal.

\section{Problem Cataloging Index (PCI)}

For identification of most important environmental issues in Pakistan, a problem cataloging index (PCI) was applied to all environmental issues and then all environmental issues were ranked based on their estimated PCI value. Farmers were asked to rate their perceptions about each environmental issue on a Likert scale, i.e., ranging from very important to not important at all, also including a "don't know" option. Frequencies for each level of response for each environmental issue were multiplied by a weight of from 5 to 0 ( 5 for very important and 0 for don't know), and then a PCI value was generated by adding all weighted frequencies. Finally, all environmental issues were ranked on the basis of their estimated PCI value. The PCI value was estimated using the formula below:

$$
\begin{array}{r}
\mathrm{PCI}=\mathrm{P}_{\mathrm{VI}} \times 5+\mathrm{P}_{\mathrm{I}} \times 4+\mathrm{P}_{\mathrm{LI}} \times 3 \\
+\mathrm{P}_{\mathrm{NI}} \times 2+\mathrm{P}_{\mathrm{NIA}} \times 1+\mathrm{P}_{\mathrm{DK}} \times 0
\end{array}
$$

...where:

$\mathrm{PCI}=$ Problem Cataloging Index

$\mathrm{P}_{\mathrm{VI}}=$ Number of farmers who rated the environmental problem as very important

$\mathrm{P}_{\mathrm{I}}=\ldots$ important

$\mathrm{P}_{\mathrm{LI}}=\ldots$ less important

$\mathrm{P}_{\mathrm{NI}}=\ldots$ not important

$\mathrm{P}_{\mathrm{NIA}}=\ldots$ not important at all

$\mathrm{P}_{\mathrm{DK}}=\ldots$ don't know

A constraint index was applied to identify the degree of different constraints faced by the farmers while adapting to climate change. Values of the constraint index were estimated using the equation below:

$$
\mathrm{CI}=\mathrm{P}_{\mathrm{H}} \times 3+\mathrm{P}_{\mathrm{M}} \times 2+\mathrm{P}_{\mathrm{L}} \times 1+\mathrm{P}_{\mathrm{N}} \times 0
$$

$\mathrm{CI}=$ Constraint Index

$\mathrm{P}_{\mathrm{H}}=$ Number of farmers who graded a high degree of constraint

$\mathrm{P}_{\mathrm{M}}=\ldots$ a medium degree of constraint

$\mathrm{P}_{\mathrm{L}}=\ldots$ a low degree of constraint

$\mathrm{P}_{\mathrm{N}}=\ldots$ no constraint

\section{Weighted Average Index (WAI)}

A framework of weighted average index (WAI) was used to understand farmers' trust on information sources about climate change. Farmers were asked to highlight their level of trust on different sources of information on a Likert scale, where 1 indicates least trust on a particular source of information while 4 represents a lot of trust. 0 indicates a farmer's inability to choose any trust level.

$$
W A I=\sum F i W i / \sum F i
$$

...where "WAI" is the weighted average index, "F" is the frequency of response and " $\mathrm{W}$ " is the weight of each score; and $\mathrm{i}=$ score, i.e., a lot $=4$, a little $=3$, not very much $=2$ not at all $=1$, can't choose $=0$.

The same methodology was used to assess farmers' views about the level of responsibility and trust on different stakeholders that were assumed to take some actions to reduce the negative consequences of climate change.

For responsibility index $\mathrm{i}=$ score, i.e., high $=3$, low $=2$, no $=1$, don't know $=0$, and

for trust index $\mathrm{i}=$ score, i.e., trust $=2$, maybe trust $=$ 1 , no trust $=0$.

\section{Results and Discussion}

A descriptive overview is generally used to get preliminary insight of the socio-economic characteristics of respondents. Therefore, age, years of 
Table 1. Farmers' Socio-Economic characteristics $(\mathrm{N}=386)$.

\begin{tabular}{|c|c|c|c|c|}
\hline Age & Mean & St. Dev & Minimum & Maximum \\
\hline HH Age (Year) & 44.77 & 10.96 & 22.00 & 82.00 \\
\hline HH Education (Year) & 6.32 & 4.27 & 0.00 & 16.00 \\
\hline Family Size (No.) & 5.73 & 1.95 & 1.00 & 11.00 \\
\hline Farming Experience (Year) & 21.38 & 10.99 & 5.00 & 60.00 \\
\hline Total Cultivated Area (Acre) & 6.10 & 7.55 & 0.50 & 67.00 \\
\hline
\end{tabular}

Source: Authors Estimations

education, family size, years of farming experience and total cultivated area are analyzed. Age reflects a sign of maturity and experience [28, 29], whereas education reflect a farmer's access to advanced ways of farming [30], while farming experience improves perception about climate change [28] and therefore helps in understanding a farmers' indigenous knowledge about climate change and agriculture. The farm area under cultivation usually serves as a proxy for a farmers' wealth that is further linked to farmers' adaptive capacity [31]. A greater labor endowment is connected to the better achievement of agricultural activities at a farm and therefore family size is an important indicator while studying farmers' adaptation to climate change. Results in Table 1 indicate that a respondent's mean age in the study area was about 45 years. Whereas mean education, family size, farming experience and total cultivated area were about 6 years, 6 members, 21 years and 6 acres, respectively. Education and landholding both were found to be lower, indicating limited capacity to engage in adaptation to climate change, whereas age and farming experience depicted enough maturity to comprehend farmers' understandings about climate change and agriculture.

Table 2. Ranking Environmental Issues using Problem Cataloging Index (PCI).

\begin{tabular}{|c|c|c|c|c|c|c|c|c|}
\hline \multirow[b]{2}{*}{ Environmental Issues } & \multicolumn{6}{|c|}{ Degree of Problem } & \multirow[b]{2}{*}{ PCI } & \multirow[b]{2}{*}{ Ranking } \\
\hline & V. Imp. & Important & $\begin{array}{c}\text { Less } \\
\text { Important }\end{array}$ & $\begin{array}{c}\text { Not } \\
\text { Important }\end{array}$ & $\begin{array}{c}\text { Not Important } \\
\text { at all }\end{array}$ & $\begin{array}{l}\text { Don't } \\
\text { Know }\end{array}$ & & \\
\hline Climate Change & 243 & 115 & 10 & 3 & 9 & 6 & 1720 & 1 \\
\hline Flooding & 302 & 27 & 6 & 14 & 36 & 1 & 1700 & 2 \\
\hline Destruction of Forests & 226 & 117 & 9 & 11 & 15 & 8 & 1662 & 3 \\
\hline Pollution (Air, Water ) & 223 & 103 & 29 & 16 & 13 & 2 & 1659 & 4 \\
\hline Traffic / Congestion & 199 & 104 & 38 & 19 & 6 & 20 & 1569 & 5 \\
\hline Overpopulation & 166 & 117 & 54 & 14 & 29 & 6 & 1517 & 6 \\
\hline Pollution of Rivers and Seas & 166 & 116 & 51 & 20 & 21 & 12 & 1508 & 7 \\
\hline Waste Disposal & 131 & 136 & 40 & 39 & 15 & 25 & 1412 & 8 \\
\hline Poor Waste Management & 133 & 116 & 55 & 28 & 28 & 26 & 1378 & 9 \\
\hline Radioactive Waste & 124 & 127 & 41 & 21 & 32 & 41 & 1325 & 10 \\
\hline Litter & 111 & 112 & 67 & 32 & 38 & 26 & 1306 & 11 \\
\hline Use of Pesticides & 134 & 84 & 44 & 58 & 47 & 19 & 1301 & 12 \\
\hline Use of Nuclear Power & 123 & 93 & 34 & 39 & 38 & 59 & 1205 & 13 \\
\hline Using up earth's resources & 102 & 81 & 85 & 40 & 18 & 60 & 1187 & 14 \\
\hline Loss of Wildlife Habitats & 80 & 100 & 77 & 56 & 41 & 32 & 1184 & 15 \\
\hline Extinction of Species & 87 & 77 & 110 & 34 & 31 & 47 & 1172 & 16 \\
\hline Genetically Modified Crops & 84 & 76 & 34 & 103 & 51 & 38 & 1083 & 17 \\
\hline Hole in Ozone Layer & 95 & 80 & 39 & 26 & 45 & 101 & 1009 & 18 \\
\hline
\end{tabular}

Source: Authors Estimations 
Table 3. Farmers' Trust on Climate Information through Weighted Average Index (WAI).

\begin{tabular}{|c|c|c|c|c|c|c|c|}
\hline \multirow{2}{*}{ Source of Information } & \multicolumn{3}{|c|}{ Degree of Trust } & \multirow{2}{*}{ WAI } & \multirow{2}{*}{ Ranks } \\
\cline { 2 - 7 } & A lot & A little & Not very much & Not at all & Can't Choose & \\
\hline A Scientist/ Expert & 288 & 44 & 30 & 17 & 7 & 3.53 & 1 \\
\hline The Media (Television, Radio, Newspapers) & 236 & 91 & 35 & 19 & 5 & 3.38 & 2 \\
\hline A Family member or Friend & 182 & 101 & 82 & 20 & 1 & 3.15 & 3 \\
\hline Environmental Organization & 149 & 94 & 58 & 56 & 29 & 2.72 & 4 \\
\hline
\end{tabular}

Source: Authors Estimations

\section{Results of Problem Cataloging Index}

Results demonstrated in Table 2 highlight thoughtprovoking findings about different environmental issues in Pakistan. Among 18 presented environmental snags, climate change was recognized as the largest environmental issue, whereas the top five most important environmental issues were flooding, destruction of forests, pollution, traffic/congestion and overpopulation. Government should prioritize their policies about the environment while considering indigenous knowledge about different environmental issues in Pakistan.

\section{Farmers' Trust of Information about Climate Change}

There are always some common sources of information for every individual in any society, but the level of trust varies in different regions; therefore, farmers' trust on climate change information was evaluated so that better climate information dissemination may be suggested, which is a key factor in an efficient climate policy. Four different sources of information were presented to farmers, i.e., a family member or friend, a scientist, environmental organizations and the media (television, radio, and newspaper etc.), and scale of trust was ranked from a lot of trust to no trust with an option to not choose that indicates an inability to choose any trust level.

Results of weighted average index in Table 3 exhibited scientist and the media as the two most trusted sources of information, while a family member or friend and environmental organizations were also trusted by farmers but less than the media and scientists. Hence, scientists and the media are considered the two most operational and effective sources in educating farmers about climate change and improved climate information dissemination.

\section{Level of Responsibility and Trust on Different Stakeholders in Society}

While considering the effective application of climate change policy stakeholders, such as government, local councils, business and industry, environmental organizations, individuals and citizens, family and friends and myself are assumed to be responsible for making any changes to limit the negative consequences of climate change. Famers' views were captured on a Likert scale indicating level of responsibility from high to low, including no responsibility, whereas trust was estimated on a Likert scale from high to low trust, including no trust.

Results in Fig. 1 indicated government, local councils and business and industry as highly responsible for making any changes to lessen the impacts of climate change. While studying level of trust, highly responsible stakeholders were indicated as not trusted by most of the respondents. An interesting finding about environmental organizations was observed, although they were considered less responsible but they were trusted. This may be due to the recent active role of environmental organizations in responding to negative impacts of climate change.

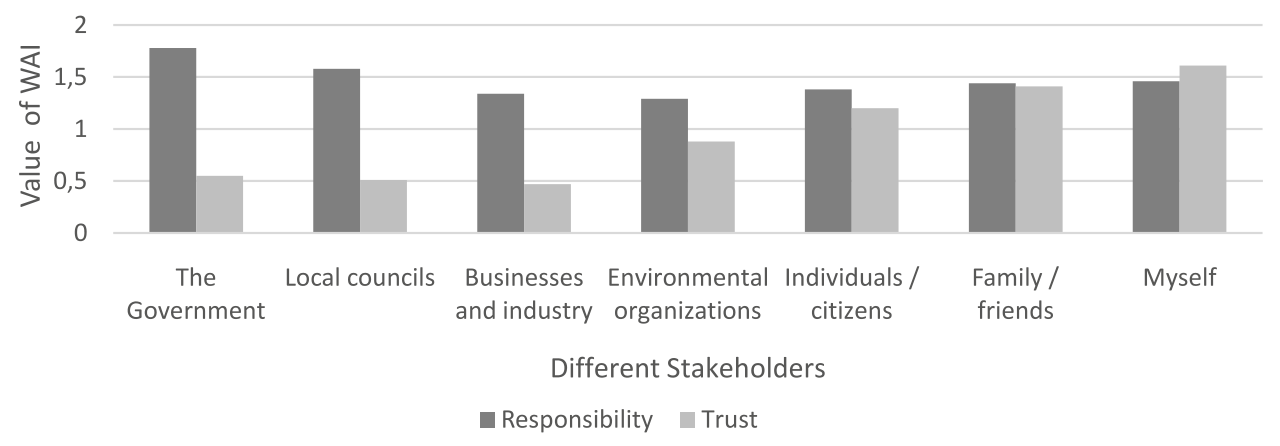

Fig. 1. Level of Responsibility and Trust on different stakeholders in society. 


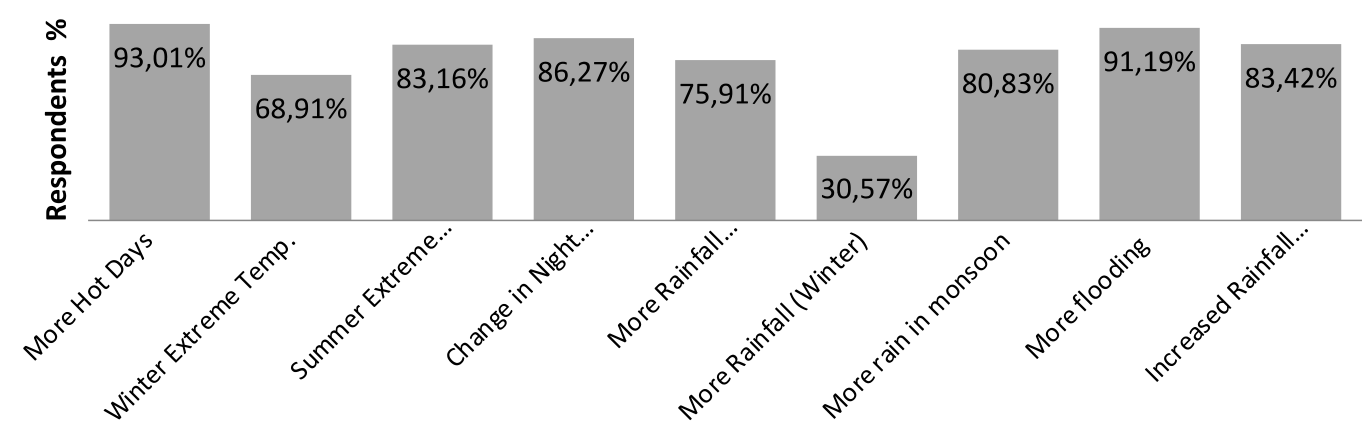

Fig. 2. Farmers' Perception about climate indicators.

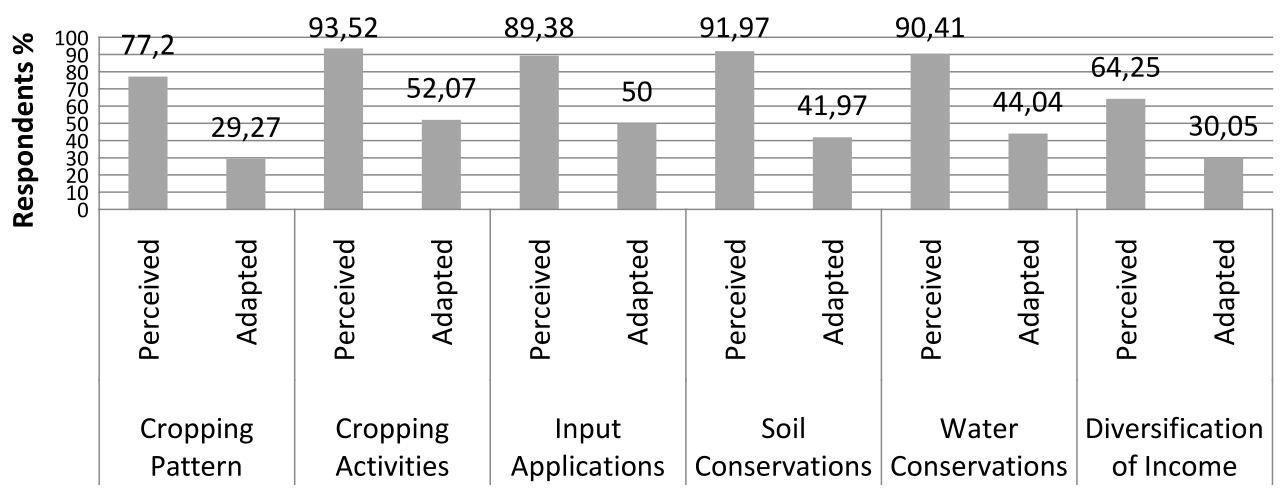

Fig. 3. Different Adaptation Strategies to climate change.

\section{Farmers' Perceptions about Climate Change and Adaptation to Climate Change}

Farmers' perceptions about different climate indicators described in Fig. 3 highlight how farmers perceive climate change, hence indicating different changes in local climate based on their past 20 years of experience [32]. Farmers observed more hot days, extreme temperatures in both seasons (i.e., summer and winter), change in nighttime temperature, and more rainfall (particularly in monsoon), increased rainfall intensity and more flooding.
Farmers' perceived responses or adaptation practices to changes in local climate and adaptations undertaken are highlighted in Fig. 3. Most farmers have perceived changes in local farming, but very few of them have adapted to perceived changes in farming due to several constraints. Farmers perceive changes in cropping patterns (77\%), cropping activities (94\%), input applications (89\%), soil conservation (92\%), water conservation $(90 \%)$ and diversification of income, but only about $29 \%$ of farmers have adapted in cropping patterns. Similarly, about 52\%, 50\%, 42\%, 44\% and 30\% of farmers have adapted in cropping activities, input

Table 4. Constraints in Adapting to Climate Change.

\begin{tabular}{|c|c|c|c|c|c|c|}
\hline \multirow[t]{2}{*}{ Constraints } & \multicolumn{4}{|c|}{ Degree of Constraint } & \multirow{2}{*}{ PCI } & \multirow{2}{*}{ Ranks } \\
\hline & High & Medium & Low & No & & \\
\hline Lack of Money & 153 & 96 & 81 & 56 & 732 & 1 \\
\hline High Cost of Farm Inputs & 134 & 105 & 87 & 60 & 699 & 2 \\
\hline Lack of Knowledge about Appropriate Adaptations & 127 & 111 & 93 & 55 & 696 & 3 \\
\hline Lack of Irrigation Resources & 131 & 99 & 86 & 70 & 677 & 4 \\
\hline Lack of Climate Information & 123 & 84 & 107 & 72 & 644 & 5 \\
\hline Lack of Market Access & 57 & 80 & 111 & 138 & 442 & 6 \\
\hline Insecure Property Rights & 41 & 70 & 68 & 207 & 331 & 7 \\
\hline
\end{tabular}

Source: Authors Estimations 
applications, soil conservation, water conservation and diversification of income, respectively. A comprehensive adaptation strategy can only be achieved by identifying the constraints in adaptation processes that create gaps in perceived and adapted strategies.

\section{Constraints in Adapting to Climate Change}

Degrees of different constraints were explored through the constraint index (CI). Results in Table 4 highlight the lack of money, high cost of farm inputs and lack of knowledge about appropriate adaptations being the major constraints while adapting to climate change. Whereas among other constraints farmers indicate lack of irrigation resources, lack of climate information, lack of market access and insecure property rights. These constraints can be avoided by enhancing institutional support and capacity for local farmers and by enhancing the outreach of the extension department.

\section{Conclusion and Policy Implications}

Our study prioritizes the important environmental issues that will help policy makers and government to formulate more effective ways to cope with environmental challenges. Climate change was found as the biggest environmental problem, whereas flooding, destruction of forests, pollution, traffic/congestion and overpopulation were also categorized as major environmental problems in Pakistan. For better climate information dissemination and farmers' education about climate change, scientists and the media considered the two most operational and effective sources. In order to handle the issue of climate change, government, local councils and business and industry were thought to be responsible, but, they were not trusted. Although farmers perceived that climate is changing rapidly, a few of them adapted accordingly due to many constraints. Lack of money, the high cost of farm inputs and lack of knowledge about appropriate adaptations, lack of irrigation resources and lack of climate information were the major constraints farmers were facing while adapting to climate change. These constraints in the adaptation process can be avoided by providing institutional support to local farmers and by improving the services of the extension department.

This study suggests integrating indigenous knowledge and locally relevant adaptation strategies while designing local and national adaptation initiatives. It can only be achieved by creating local knowledge centers where inclusion of indigenous people in the decision-making process will help in understanding the limitations and opportunities on a smaller scale. Further research, documentation and dissemination of indigenous knowledge in all agro-ecological zones of Pakistan is also suggested, which will further help policy makers to collaborate with local residents for the formulation of more cost-effective, participatory and sustainable ways out to climate change adaptation and mitigation strategies and also effectively deal with the crisis of climate change.

\section{Conflict of Interest}

The authors declare no conflict of interest.

\section{References}

1. NZUMA J.M. Strategies for Adapting to Climate Change in Rural Sub-Saharan Africa A Review of Data Sources, Poverty Reduction Strategy Programs ( PRSPs ) and National Adaptation Plans for Agriculture ( NAPAs ) in ASARECA Member Countries. Food Policy, 1013 (July), 64. Retrieved from http://www.eis-africa.org/EISAfrica/2ifpri_review.pdf 2010.

2. MANANDHAR S., VOGT D.S., PERRET S.R., KAZAMA F. Adapting cropping systems to climate change in Nepal: A cross-regional study of farmers' perception and practices. Regional Environmental Change, 11 (2), 335, 2011.

3. APPIAH-APPIAH-OPOKU S. Need for indigenous knowledge in environmental impact assessment. Edwin Mellen Press. 2005.

4. NUMBERS T. Annua D saster Statistical Review. 2007.

5. Germanwatch, 2013. Global Climate Risk Index, Retrieved Novemebr 25, 2013. http://Germanwatch.org/de/ download/7170.pdf. 2013.

6. KREFT S., ECKSTEIN D., JUNGHANS L., KERESTAN C., HAGEN U. Global climate risk index 2015: who suffers most from extreme weather events? Weather-related loss events in 2013 and 1994 to 2013. (n.d.)

7. ARSHAD M., KÄCHELE H., KRUPNIK T.J., AMJATHBABU T. S., ARAVINDAKSHAN S., ABBAS A., MÜLLER K. Climate variability, farmland value, and farmers' perceptions of climate change: implications for adaptation in rural Pakistan. International Journal of Sustainable Development \& World Ecology, 0 (0), 1, 2016.

8. SHAKOOR U., SABOOR A., ALI I., MOHSIN A.Q. Impact of Climate Change on Agriculture: Empirical Evidence From Arid Region, 48 (4), 327, 2011.

9. VOZINAKI A.E.K., KARATZAS G.P., SIBETHEROS I.A., VAROUCHAKIS E.A. An agricultural flash flood loss estimation methodology: the case study of the Koiliaris basin (Greece), February 2003 flood. Natural Hazards, 79 (2), 899, 2015.

10. TURNER N.J., CLIFTON H. "It's so different today": Climate change and indigenous lifeways in British Columbia, Canada. Global Environmental Change, 19 (2), 180, 2009.

11. JOURNAL I., CHANGE C. Addressing Climate Change with Indigenous Knowledge Raphael J . Nawrotzki and Polina Kadatska Andrews University, Department of Behavioral Sciences Addressing Climate Change with Indigenous Knowledge Abstract Key words, 2, 33, 2010.

12. BORICK C.P., RABE B. Belief in global warming on the rebound: National survey of American public opinion on climate change. Issues in Governance Studies, 44, 1, 2012.

13. HANSEN J., SATO M., RUEDY R. Perception of climate change. In Proceedings of the National Academy of Sciences 109, 2415, 2012. 
14. SPENCE A., POORTINGA W., BUTLER C., PIDGEON N.F. Perceptions of climate change and willingness to save energy related to flood experience [Letter]. Nature Climate Change, 1 (4), 46, 2011.

15. AKERLOF K., MAIBACH E.W., FITZGERALD D., CEDENO A.Y., NEUMAN A. Do people "personally experience" global warming, and if so how, and does it matter? Global Environmental Change, 23 (1), 81, 2013.

16. BRODY S.D., ZAHRAN S., VEDLITZ A., GROVER H. Examining the relationship between physical vulnerability and public perceptions of global climate change in the United States. Environment and behavior, 40 (1), 72, 2008.

17. ADGER W.N., DESSAI S., GOULDEN M., HULME M., LORENZONI I., NELSON D.R., WREFORD A. Are there social limits to adaptation to climate change? Climatic Change, 93 (3-4), 335, 2009.

18. NYONG A., ADESINA F., OSMAN ELASHA B. The value of indigenous knowledge in climate change mitigation and adaptation strategies in the African Sahel. Mitigation and Adaptation Strategies for Global Change, 12 (5), 787, 2007.

19. CHANG'A L.B., YANDA P.Z., NGANA J. Indigenous knowledge in seasonal rainfall prediction in Tanzania: A case of the South-western Highland of Tanzania. Journal of Geography and Regional Planning, 3 (April), 66. 2010.

20. GUTHIGA P., NEWSHAM A. Meteorologists Meeting Rainmakers: Indigenous Knowledge and Climate Policy Processes in Kenya. IDS Bulletin, 42 (3), 104, 2011.

21. NKOMWA E.C., JOSHUA M.K., NGONGONDO C., MONJEREZI M., CHIPUNGU F. Assessing indigenous knowledge systems and climate change adaptation strategies in agriculture: A case study of Chagaka Village, Chikhwawa, Southern Malawi. Physics and Chemistry of the Earth, 67-69, 164, 2014.

22. NAKASHIMA D.J., GALLOWAY MCLEAN K., THULSTRUP H.D., RAMOS CASTILLO A., RUBIS J.T. Weathering Uncertainty: Traditional Knowledge for Climate Change Assessment and Adaptation. In Paris, UNESCO, and Darwin, UNU, 120, 2012.
23. ROBINSON J., HERBERT D., 2001. Integrating climate change and sustainable development. International Journal of Global Environmental Issues, 1 (2), 130. 2001.

24. BELOW T.B., SCHMID J.C., SIEBER S. Farmers' knowledge and perception of climatic risks and options for climate change adaptation: a case study from two Tanzanian villages. Regional Environmental Change, 15 (7), 1169, 2015

25. UDDIN M., BOKELMANN W., ENTSMINGER J. Factors Affecting Farmers' Adaptation Strategies to Environmental Degradation and Climate Change Effects: A Farm Level Study in Bangladesh. Climate, 2 (4), 223, 2014.

26. DEVKOTA R.P., COCKFIELD G., MARASENI T.N. Perceived community-based flood adaptation strategies under climate change in Nepal. International Journal of Global Warming, 6 (1), 113, 2014.

27. NDAMANI F., WATANABE T. Farmers' perceptions about adaptation practices to climate change and barriers to adaptation: A micro-level study in Ghana. Water (Switzerland), 7 (9), 4593, 2015.

28. HASSAN R., NHEMACHENA C., HASSAN R., NHEMACHENA C., RASHID H. Determinants of African farmers' strategies for adapting to climate change: Multinomial choice analysis. AfJARE, 2 (1), 83, 2008.

29. DERESSA T.T., HASSAN R.M., RINGLER C., ALEMU T., YESUF M. Determinants of farmers' choice of adaptation methods to climate change in the Nile Basin of Ethiopia. Global Environmental Change, 19 (2), 248, 2009.

30. MADDISON D. The Perception of and Adaptation to Climate Change in Africa. Africa, (August), 1, 2007.

31. GEBREHIWOT T., VAN DER VEEN A. Farm level adaptation to climate change: The case of farmer's in the ethiopian highlands. Environmental Management, 52 (1), 29, 2013.

32. MERTZ O., MBOW C., REENBERG A., DIOUF A. Farmers' perceptions of climate change and agricultural adaptation strategies in rural sahel. Environmental Management, 43 (5), 804, 2009. 